\title{
Hubungan antara Pesan Komunikasi Keluarga di Radio Mom and Kids dengan Proses Pembelajaran Anak
}

\author{
Firda Aprilia Putri", Yenni Yuniati
}

Fakultas Ilmu Komunikasi, Universitas Islam Bandung, Indonesia.

*firdaprilliaaa@gmail.com, yenniybs@gmail.com

\begin{abstract}
This study is entitled "The Relationship Between Family Communication Messages on Radio Mom and Kids With Child Learning Process" The purpose of this study was to determine the relationship between family communication messages on Radio Mom and Kids with the learning process. Family communication is very important for family development in order to keep moving. Therefore, the family certainly still needs communication media besides social media and the internet to establish family communication. One media that can still be used is radio. In addition to its relatively inexpensive access fees, radio is also able to reach millions of listeners spread across various places with diverse geographical conditions. This research uses a quantitative method using a correlational approach. Data collection techniques used in this study are through the distribution of questionnaires to populations and samples that have been determined. The measurement scale used in the questionnaire calculation uses the ordinal measurement scale. My goal is to conduct this research to find out how the relationship between family communication messages on Radio Mom ad Kids with the learning process.
\end{abstract}

Keywords: Family Communication, Learning Process, Message

\begin{abstract}
Abstrak. Penelitian ini berjudul "Hubungan Antara Pesan Komunikasi Keluarga di Radio Mom and Kids Dengan Proses Pembelajaran Anak" Tujuan penelitian ini untuk mengetahui hubungan antara pesan komunikasi keluarga di Radio Mom and Kids dengan proses pembelajaran. Komunikasi keluarga sangat penting bagi perkembangan keluarga agar terus bergerak. Oleh karena itu keluarga tentunya masih memerlukan media komunikasi selain media sosial dan internet untuk menjalin komunikasi keluarga. Salah satu media yang masih bisa digunakan yaitu radio. Selain biaya aksesnya yang relatif murah, radio juga mampu menjangkau jutaan pendengar yang tersebar di berbagai tempat dengan kondisi geografis yang beragam. Penelitian ini menggunakan metode kuantitatif dengan menggunakan pendekatan korelasioanal. Teknik pengumpulan data yang digunakan dalam penelitian ini adalah melalui penyebaran angket kepada populasi dan sampel yang sudah ditentukan. Skala pengukuran yang digunakan dalam perhitungan angket menggunankan skala pengukuran ordinal. Tujuan saya melakuka penelitian ini untuk mengetahui bagaimana hubungan antara pesan komunikasi keluarga di Radio Mom ad Kids dengan proses pembelajaran.
\end{abstract}

Kata Kunci: Komunikasi Keluarga, Proses Pembelajaran, Pesan 


\section{A. Pendahuluan}

Komunikasi keluarga begitu penting bagi perkembangan keluarga agar terus bergerak. Komunkasi keluarga tentunya harus dilakukan oleh seluruh anggota keluarga yaitu orang tua dan anak, namun pada era modern saat ini banyak keluarga yang kurang akan komunikasi dalam keluarganya dikarenakan

masing-masing anggota yang sibuk dengan dunia maya sendiri, hal ini juga terjadi kepada sang anak. Banyak informasi, hiburan, dan kesenangan diri lainnya yang bisa ditemukan di internet khusunya media sosial. Pengaruh media sosial sangat berperan bagi nilai-nilai, etika, dan norma dalam keluarga. Jaringan internet memang sangat dibutuhkan oleh orang tua dan anak untung menjalin komunikasi, namun jika berlebihan hal tersebut bisa berdampak negatif bagi perkembangan anak dan komunikasi keluarga.

Mom and Kids radio menjadi salah satu media elektronik yang memiliki program mengenai komunikasi keluarga khususnya ibu dan anak. Mom and Kiss radio memiliki program yang mampun memberikan edukasi serta informasi dengan segmentasi untuk keluarga khususnya ibu dan anak. Mom and Kids radio didirikan agar menjadi wadah informasi atau pendidikan bagi seluruh khayalak yang mendengarkan khususnya ibu dan anak. Karena Mom and Kids radio memiliki keunikan yang mampu mengemas seluruh edukasi dan pendidikan bagi keluarga dengan lebih fun agar anak-anak yang mendengarkan lebih ceria dan juga cepat tanggap.

Radio merupakan sebuah teknologi komunikasi dengan cara mengirimkan sinyal melalui gelombang elektromagnetik. Radio merupakan medai massa auditif karena dikonsumsi telinga atau pendengaran sehingga isi siarannya bersifat sepintas dan tidak dapat diulang. Setiap radio tentunya memiliki ciri khas dan keunikan masing-masing, seperti hal nya Mom and Kids radio yang memiliki program unik yaitu edukasi dan pendidikan seputar keluarga khusunya ibu dan anak yang mendukung proses pembelajaran sang anak. Rustaman (2001: 461) mengemukakan bahwa proses pembelajaran adalah proses yang didalamnya terdapat kegiatan interaksi antara guru-siswa dan komunikasi timbal balik yang berlangsung dalam situasi edukatif untuk mencapai tujuan belajar. Radio Mom and Kids memiliki bahasa yang mudah diterima oleh pendengar dengan menyesuaikan bahasa local. Bahwa melalui radio, orang lebih in tune mendengar bahasa daerah masuk ke telinga (S.K. Santana, 2017)

Alasan peneliti membahas tentang hubungan antara pesan komunikasi keluarga di Radio Mom and Kids sebagai proses pembelajaran anak karena peneliti tertarik dengan program yang disiarkan oleh Radio Mom and Kids yang terinspirasi oleh ibu dan anak. Program di Radio Mom and Kids banyak membahas bagaimana menjadi orang tua yang baik dalam berbagai hal termasuk berkomunikasi dengan anak, hal tersebut menarik perhatian peneliti terhadap pesan komunikasi keluarga sebagai proses pembelajaran anak.

Berdasarkan fenomena yang telah dipaparkan, peneliti merumuskan masalah sebagai

berikut: "Bagaimana hubungan antara pesan komunikasi keluarga di Radio Mom and Kids dengan proses pembelajaran anak?". Yang

penulis uraikan dalam pokok-pokok bahasan sebagai berikut:

1. Hubungan antara sumber komunikasi di Radio Mom and Kids dengan proses pembelajaran anak.

2. Hubungan pesan yang disampaikan Radio Mom and Kids dengan proses pembelajaran anak.

3. Hubungan media yang digunakan Radio Mom and Kids dengan proses pembelajaran anak.

4. Hubungan penerima pesan Radio Mom and Kids dengan proses pembelajaran anak.

\section{B. Landasan Teori}

Komunikasi adalah keadaan yang terjadi pada dua orang atau lebih dengan adanya pertukaran informasi dengan maksud dan tujuan tertentu. Secara umum komunikasi dapat diartikan sebagai proses pengiriman dan penerimaan pesan yang dilakukan oleh dua orang atau lebih secara efektif sehingga dapat menjadi komunikasi yang berhasil. Menurut Nurudin (2016: 168) proses 
komunikasi adalah usaha menyampaikan suatu gagasan untuk menerima umpan balik dari gagasan yang kita sampaikan. Dalam kehidupan sehari-hari tentunya manusia membutuhkan komunikasi pada setiap tindakannya. Komunikasi bermacam-macam bentuk, salah satunya komunikasi keluarga. Setiap keluarga menginginkan komunikasi yang intensif, dinamis dan harmonis. Hafied Cangara (2002: 62) mengemukakan fungsi komunikasi dalam keluarga yaitu meningkatkan hubungan insani (Human Relation), mengatasi dan meminimalisir konflikkonflik pribadi dalam keluarga, mengurangi sesuatu yang belum pasti, dan berbagi satu sama lain tentang pengetahuan dan pengalaman. Hubungan diantara pihak-pihak yang berkomunikasi dapat ditingkatkan dengan adanya komunikasi dalam keluarga.

Beberapa unsur yang dilakukan dalam sebuah komunikasi keluarga menurut Hafied Cengara (2002: 62) yaitu sebagai berikut:

1. Sumber Komunikasi

Sumber komunikasi adalah pembuat atau pengirim informasi dalam komunikasi keluarga.

2. Pesan

Pesan yang disampaikan pada proses komunikasi dalam keluarga dapat disampaikan dengan cara tatap muka di dalam rumah atau melalui media komunikasi bisa tidak bertemu secara langsung.

3. Media

Media yang dimaksud adalah alat yang digunakan untuk memindahkan pesan dari sumber kepada penerima.

4. Penerima Pesan

Penerima adalah pihak yang menjadi sasaran pesan. Di dalam keluarga, penerima pesan adalah semua anggota keluarga . unsur lain adalah pengaruh atau efek pesan baik dari pengetahuan, sikap atau tingkah laku seseorang.

Media massa dapat diartikan sebagai jembatan untuk menyalurkan dan mempublikasikan informasi kepada publik atau masyarakat. Menurut Soehadi (1978:38), "Media adalah bentuk jamak dari medium yang berarti tengah atau perantara. Masa berasal dari bahasa Inggris yaitu mass yang berarti kelompok atau kumpulan. Dengan demikian, pengertian media massa adalah perantara atau alat- alat yang digunakan oleh massa dalam hubungannya satu sama lain".

Proses pembelajaran yang dilalui oleh anak-anak yaitu dengan cara bermain. Dengan bermain tentu mempengaruhi perkembangan sosial dan emosional anak pada umumnya. Anak yang bermain akan merasakan berbagai macam emosi, senang, sedih, bangga, marah, dan sebagainya. Bermain juga merupakan faktor bagi anak untuk memahami kaitan antara dirinya dan lingkungan sosialnya, belajar bergaul maupun tata krama pergaulan. Namun teori pembelajaran dan teori belajar tentu berbeda.Menurut Bruner (Siregar dan Hartini, 2014: 23), teori pembelajaran adalah perskriptif dan teori belajar adalah deskriptif. Perskriptif karena tujuan utama teori pembelajaran adalah metode pembelajaran yang optimal, sedangkan teori belajar atau deskriptif karena tujuan utama teori belajar adalah menjelaskan proses belajar.

\section{Hasil dan Pembahasan Sumber Komunikasi}

Analisis Deskriptif Data Responden dilakukan dengan tujuan untuk memberikan gambaran mengenai objek penelitian berdasarkan data dan variabel yang dperoleh dari kelompok subjek yang diteliti. Dalam penelitian ini penulis yaitu pendengar setia Radio Mom and Kids berdasarkan data pengunjung event Radio Mom and Kids sebanyak 148 orang. Data sampel dalam penelitian ini diperoleh dengan cara memilih acak, dari populasi sebanyak 148 orang sampel yang sudah dipersempit siperoleh sebanyak 60 orang. Data identitas seluruh responden diperoleh dengan cara mengisi daftar hadir ketika mengikuti event, namun penulis ingin memperoleh data identitas responden yang lebih akurat sehingga dilakukan pengajuan pertanyaan yang berhubungan dengan nama, jenis kelamin, dan nomor telepon yang aktif. Data tersebut kemudian dilampirkan dalam bentuk tabel yang disertai dengan analisis. 
Data jawaban dari pertanyaan pertama menunjukan bahwa sebanyak 5\% responden tidak setuju apabila penyiar Radio Mom and Kids memiliki keahlian dalam menyampaikan informasi di radio, sebanyak 83,3\% responden setuju apabila penyiar Radio Mom and Kids memiliki keahlian dalam menyampaikan informasi di radio, dan sebanyak $11,7 \%$ responden sangat setuju apabila penyiar Radio Mom and Kids memiliki keahlian dalam menyampaikan informasi di radio. Data dari pertanyaan kedua menunjukan bahwa 5\% responden tidak setuju apabila penyiar Radio Mom and Kids memiliki keahlian dalam menyampaikan informasi di radio, 56,7\% responden setuju apabila penyiar Radio Mom and Kids memiliki keahlian dalam menyampaikan informasi di radio, 38,3\% responden setuju apabila penyiar Radio Mom and Kids memiliki keahlian dalam

menyampaikan informasi di radio.Data dari pertanyaan ketiga menunjukan bahwa 5\% responden tidak setuju apabila penyiar Radio Mom and Kids menarik perhatian anda dalam mengajak pendengar untuk beredukasi, 55\% responden setuju apabila penyiar Radio Mom and Kids menarik perhatian anda dalam mengajak pendengar untuk beredukasi, $40 \%$ responden setuju apabila penyiar Radio Mom and Kids menarik perhatian anda dalam mengajak pendengar untuk beredukasi.Data dari pertanyaan keempat menunjukan bahwa 6,7\% responden tidak setuju apabila penyiar Radio Mom and Kids informatif dalam memberikan informasi, 36,7\% responden setuju apabila penyiar Radio Mom and Kids informatif dalam memberikan informasi, 56,7\% responden setuju apabila penyiar Radio Mom and Kids informatif dalam memberikan informasi.

Kesimpulannya adalah terdapat hubungan antara pesan komunikasi keluarga di Radio Mom and Kids dengan proses pembelajaran anak. Karena unsur- unsur pesan komunikasi keluarga salahsatunya adalah sumber komunikasi yang telah dibuat menjadi empat pertanyaan bagi responden sehingga respon yang diterima oleh penulis yaitu terdapat hubungan sumber komunikasi pesan komunikasi keluarga dengan proses pembelajaran anak.

\section{Pesan}

Data jawaban dari pertanyaan diatas menunjukan bahwa sebanyak 5\% responden tidak setuju apabila intonasi penyiar Radio Mom and Kids dalam menyampaikan pesan berhubungan dengan pendengar, sebanyak 45\% responden setuju apabila intonasi penyiar Radio Mom and Kids dalam menyampaikan pesan berhubungan dengan pendengar, dan sebanyak 50\% responden sangat setuju apabila intonasi penyiar Radio Mom and Kids dalam menyampaikan pesan berhubungan dengan pendengar. Kesimpulannya adalah terdapat hubungan dengan pesan yang disampaikan Radio Mom and Kids dengan proses pembelajaran anak. Karena pesan nonverbal yang disampaikan adalah sebagai sumber informasi untuk membentu persepsi kita terhadap orang lain. Dalam penelitian ini menunjukan bahwa responden atau pendengar Radio Mom and Kids sangat setuju apabila intonasi penyiar Radio Mom and Kids dalam menyampaikan pesan berhubungan dengan pendengar. Karena pesan yang disampaikan oleh penyiar Radio Mom and Kids dapat diterima dengan jelas oleh pendengar melaluli intonasi yang jelas.

\section{Media Massa Radio}

Data jawaban dari pertanyaan diatas menunjukan bahwa sebanyak 5\% responden tidak setuju apabila kualitas penyiar Radio Mom and Kids sangat baik untuk didengar, sebanyak 38,3\% responden setuju apabila pkualitas penyiar Radio Mom and Kids sangat baik untuk didengar, sebanyak 56,7\% responden sangat setuju apabila kualitas penyiar Radio Mom and Kids sangat baik untuk didengar.

Kesimpulannya adalah terdapat hubungan menyangkut dengan media massa Radio Mom and Kids dengan proses pembelajaran anak. Karena komunikasi akan dinilai sempurna ketika terdapat media diantaranya, pesan yang disampaikan harus melalui suatu media agar dapat diterima dengan mudah dan jelas oleh penerima komunikasi. Dalam penelitian ini responden atau pendengar Radio Mom and Kids sangat setuju apabila kualitas penyiar Radio Mom and Kids sangat baik untuk didengar melalui media massa Radio Mom and Kidskarena membantu proses komunikasi yang dilakukan. 


\section{Penerima Pesan}

Data jawaban dari pertanyaan pertama menunjukan bahwa sebanyak $0 \%$ atau tidak ada responden tidak setuju apabila Apakah anda setuju apabila dengan mendengarkan penyiar Radio Mom and Kids dapat menambah pengetahuan, sebanyak 53,3\% responden setuju apabila Apakah anda setuju apabila dengan mendengarkan penyiar Radio Mom and Kids dapat menambah pengetahuan, sebanyak 46,7\% responden sangat setuju apabila Apakah anda setuju apabila dengan mendengarkan penyiar Radio Mom and Kids dapat menambah pengetahuan.

Data jawaban dari pertanyaan kedua menunjukan bahwa sebanyak 3,3\% responden tidak setuju apabila dengan mendengarkan penyiar Radio Mom and Kids dapat menambah pengetahuan, sebanyak 50\% responden setuju apabila dengan mendengarkan penyiar Radio Mom and Kids dapat menambah pengetahuan, sebanyak 46,7\% responden sangat setuju apabila dengan mendengarkan penyiar Radio Mom and Kids dapat menambah pengetahuan.

Kesimpulannya adalah terdapat hubungan menyangkut dengan penerima pesan Radio Mom and Kids dengan proses pembelajaran anak berdasarkan hasil pertanyaan angket pada pertanyaan diatas yaitu responden setuju dengan pertanyaannya. Karena penerima pesan adalah elemen yang terpenting dalam menjalankan sebuah proses komunikasi.

\section{Proses Pembelajaran}

Data jawaban dari pertanyaan diatas menunjukan bahwa sebanyak $8,3 \%$ responden tidak setuju apabila penyiar Radio Mom and Kids menjadi media belajar anak, sebanyak 45\% responden setuju apabila penyiar Radio Mom and Kids menjadi media belajar anak, sebanyak 46,7\% responden sangat setuju apabila $f$ penyiar Radio Mom and Kids menjadi media belajar anak. Kesimpulannya adalah terdapat hubungan menyangkut dengan pesan komunikasi Radio Mom and Kids dengan proses pembelajaran anak berdasarkan hasil jawban yang diterima penulis dari responden. Responden menyatakan sangat setuju apabila penyiar Radio Mom and Kids menjadi media belajar anak. Karena proses pembelajaran adalah upaya membelajarkan siswa berdasarkan asas pendidikan maupun teori belajar yang merupakan penentu utama keberhasilan pendidikan.

Selanjutnya data yang diperoleh, dianalisis menggunakan uji validitas, uji reliabilitas dan uji korelasional bivariate. Berdasarkan hasil uji validitas instrumen penelitian didapatkan nilai $r$ hitung tiap butir pertanyaan menunjukkan lebih besar daripada $r$ tabel. Oleh karena itu, butir pertanyaan instrumen yang digunakan seluruhnya dinyatakan valid karena $r_{\text {hitung }}>r_{\text {tabel }}$.

Berdasarkan hasil perhitungan reliabilitas instrument penelitian variable $\mathrm{X}$ dan $\mathrm{Y}$, didapatkan nilai reliabilitas untuk variabel $\mathrm{X}$ sebesar 0,705 dan untuk variabel $\mathrm{Y}$ sebesar 0,698. reliabilitas instrumen penelitian untuk variabel $X$ dan variabel dengan $r$ tabel sebesar 0,254 dikatakan reliabel atau konsisten.

Hasil pengujian uji kolerasi dari hipotesis yang diujikan. Berdasarkan teori yang dikemukakan oleh Suhartanto (2014), variabel yang memiliki nilai signifikansi diatas 0.05 merupakan variabel yang tidak berkolerasi. Dari data yang dihasilkan terdapat nilai yang signifikan antara gaya kepemimpinan sebagai variabel independen dengan kebutuhan informasi sebagai variabel dependennya. Nilai yang dihasilkan adalah sebesar 0.000 yang artinya bahwa variabel independen secara langsung memiliki kolerasi atau hubungan yang kuat terhadap variabel pesan komunikasi keluarga.

\section{Kesimpulan}

Berdasarkan hasil penelitian yang dilakukan dengan menggunakan teknik penyebaran kuisioner kepada pendengar Radio Mom and Kids, maka peneliti menarik kesimpulan sebagai berikut:

1. Adanya hubungan antara sumber komunikasi di Radio Mom and Kids dengan proses pembelajaran anak. Dapat dilihat dari hasil kuisioner, bahwa pada dasarnya sumber komunikasi memiliki unsur- unsur, menurut (Hovland and Weiss, 1951) terdapat tiga unsur yang mempengaruhi efektivitas sumber yaitu Crediblity, Attractiveness, dan Source Power yang disebut sebagai ethos. Sehingga pada penelitian ini terdapat hubungan Credibility (Kepercayaan), Attractiveness (Daya Tarik), Source Power (Kekuatan) di Radio Mom and Kids dengan proses pembelajaran anak yang didominasi 
oleh jawaban pendengar Radio Mom and Kids yang setuju akan pernyataan- pernyataan tersebut.

2. Adanya hubungan antara pesan komunikasi di Radio Mom and Kids dengan proses pembelajaran anak. Dapat dilihat dari hasil kuisioner, bahwa pesan non verbal dapat berpengaruh pada setiap persepsi manusia. Dalam penelitian ini menunjukan bahwa pendengar Radio Mom and Kids sangat setuju apabila intonasi penyiar Radio Mom and Kids dalam menyampaikan pesan berhubungan dengan pendengar.

3. Adanya hubungan media massa Radio Mom and Kids dengan proses pembelajaran anak. Karena pada proses komunikasi yang terjalin pada penelitian ini menggunakan media massa radio. Dapat dilihat dari hasil kuisioner, bahwa pendengar Radio Mom and Kids sangat setuju apabila kualitas penyiar Radio Mom and Kids sangat baik untuk didengar. Adanya hubungan penerima pesan di Radio Mom and Kids dengan proses pembelajaran anak. Dapat dilihat dari hasil kuisioner, bahwa pedengar Radio Mom and Kids setuju apabila penyiar Radio Mom and Kids berhubungan dengan sikap anak dalam proses pembelajaran dan setuju apabila dengan mendengarkan penyiar Radio Mom and Kids dapat menambah pengetahuan.

4. Empat indikator komunikasi keluarga di Radio Mom and Kids ini selalu berhubungan dengan indikator variabel y yaitu proses pemlebajaran anak. (Syaiful Sagala, 61:2009), Pembelajaran adalahn"membelajarkan siswa menggunakan asas pendidikan maupun teori belajar yang merupakan penentu utama keberhasilan pendidikan". Karena dengan mendengarkan program siran Radio Mom and Kids dapat membantu orang tua dalam proses pembelajaran anak. Sehingga terdapat hubungan antara pesan komunikasi di Radio Mom and Kids dengan proses pembelajaran anak.

\section{Daftar Pustaka}

[1] Cangara, Hafied. 2002. Pengantar Ilmu Komunikasi. Jakarta : PT Raja GrafindoPersada) Hlm.62

[2] Jalaluddin Rakhmat.Dr., M.S.c. 2019. Psikologi Komunikasi Edisi Revisi. Bandung: Simbiosa Rekamata Media Hlm.318

[3] Nurudin.Ilmu Komunikasi Ilmiah dan Populer. (Jakarta2016: PT. Raja GrafindoPersada) Hlm 168

[4] Rustaman, N \& Rustaman A, 2001. "Keterampilan Bertanya dalam Pembelajaran IPA ”(Dalam Hand Out Bahan Pelatihan Guru-guru IPA SLTP Se-kota Bandung di PPG IPA, Depdiknas. Hal. 461)

[5] Sagala, Syaiful, 2009. Konsep dan Makna Pembelajaran. (Bandung:Alfabeta)

[6] Santana, Septiawan. 2017. Jurnalistik Kontemporer. Jakarta: Yayasan. Obor Indonesia

[7] Siregar, Eveline \& Hartini Nara. Teori Belajar dan Pembelajaran (Bogor2014:Galia Indonesia) Hlm.23

[8] Soehadi, Burhan. 1978. Media Komunikasi Masa dan Perannya dalamPembentukan Opini publik. Medan : Fakultas Hukum Usu

[9] Sugiyono. 2013. Metode Penelitian Kuantitatif, Kualitatif dan R\&D. Bandung:Alfabeta

[10] Suhartanto, Dwi. 2014. Metode Riset Pemasaran. (Bandung: Alfabeta) 